\title{
The Theory of the Political Spectrum
}

\author{
Allen Gindler
}

\begin{abstract}
This article introduces a new approach to the problem of political spectrum polarization. Political science has introduced a multitude of spectrograms based on different factors, dimensions, axes, and cardinal points. Most often the graphics do not complement each other, and it seems that each of them describes a completely different reality. There was an urgent need to conduct an objective analysis of political philosophies and find the factors that influence political spectrum polarization. An unbiased rubric to evaluate political doctrines would enable a more accurate understanding of political ideologies. To this end, thirteen political doctrines were analyzed using qualitative comparative analysis, which introduced objectivity to the study due to its use of a formalized mathematical apparatus of the theory of sets. It was found that spectrum polarization depends on three conditions: attitudes toward private property, individual freedom, and wealth redistribution. As the factors that influence political spectrum polarization were firmly determined, it became possible to build a spectrogram unambiguously.
\end{abstract}

In the course of evolution, people have formulated many philosophical ideas concerning the socioeconomic structure of society. Some of these ideas became a reality, while others remained purely imaginary constructs. All real and abstract socioeconomic ideas constitute the political spectrum. Humans have habitually tried to classify and visualize political variety in order to make sense of its structure and find a proper place for their world views. Thus, the political spectrum is most often understood as a graphic representation of

\footnotetext{
Allen Gindler (agindler@cyberrex.com) is a scholar from the former USSR specializing in political economy, econometrics, and industrial engineering. He taught economic cybernetics, standard data systems, and computer-aided work design in the Khmelnytskyi National University, Ukraine. He is currently a private consultant to IT industry on database administration and cryptography.
} 
various politico-philosophical positions on diverse issues that are relevant to a given society in a certain period of time.

This definition implies that the political spectrum is not only historical but multidimensional. The specific time frame is extremely important, as some issues that are relevant now were not considered in the past. Different eras produce different social issues, and the weight of these issues changes accordingly. For example, the legalization of marijuana or same-sex marriage was not a problem that worried society a century ago. Some questions have stood the test of time; they were prominent in the past and they are relevant now. Such eternal questions include concerns about individual freedom and attitudes toward property, justice, and civil rights, to name a few.

Humankind has developed a practice of solving issues comprehensively by creating political philosophies or ideologies that suggest solutions to the main issues in a packaged form. People can choose from among bundled solutions by clinging to this or that ideology. These ideologies suggest different ways of solving problems facing society. The more backward a society, the fewer questions are tackled through political doctrine. There is also interconnection between issues within a political ideology: the solution to some problems depends on the solution to others. Every ideology must have its own answer to the questions. Political doctrine cannot be silent on actual societal problems; otherwise, it will be ignored by people.

Historians have traced the most common and long-standing "left-right" political spectra to seating arrangements in the French Parliament after the revolution (1789-99). As the story goes, the aristocracy sat on the privileged seats at the right; their agenda was to preserve an existing state of affairs. Commoners occupied the left wing; they were for laissez-faire commerce and civil liberties (Knapp and Wright 2001). Since then, agents of the status quo have been associated with the right wing and representatives of change have been linked to the left wing. Therefore, in people's perceptions, leftist ideologies are actively seeking modifications to the existing socioeconomic formation, while the right-wingers are proponents and keepers of the existing order.

\section{THE POLITICAL SPECTRUM DYNAMICS}

At the time of the French Revolution, when the original left-right political spectrum was born, French society had a straightforward 
structure composed of the aristocracy, the clergy, and commoners. A political struggle was staged between the nobility on one side and everybody else on the other. At that time, the political spectrum exhibited a pronounced dichotomy.

It was the epoch of feudalism's swan song, in which Western European countries battled with outdated feudalism. Ultimately, feudal aristocracy lost to capitalism. Capitalism was a left-wing agent of change, and feudalism represented the right-wing preservation of the status quo. Indeed, the nobility and clergy identified commoners as radical leftists. The latter sought to restrict the nobles' power, privileges, and wealth.

After the victory of the bourgeois democratic revolutions in the overwhelming majority of European countries, from the midnineteenth century to the beginning of the twentieth century, the political situation changed. During capitalism's advance, the political spectrum developed in two distinct ways based on two events.

The first event was a switch of the political spectrum's polarization. Using the terminology of the one-dimensional political spectrum introduced by the French, the former left became the Right and vice versa. Absolutism was defeated and joined the ranks of outdated ideologies. The free market ideology began to take the right-wing position, because its supporters were committed to maintaining the new status quo. It should be noted that the destruction of the capitalist democratic state by the Bolsheviks, Fascists, and Nazis all led to a switch in the polarization of the political spectrum in their respective regions. However, under totalitarian regimes, this change was camouflaged by the collapse of legal political activity, which was expressed as a ban on dissent. Based on the foregoing, it is tempting to originate a common sociopolitical law that states: the socioeconomic changes in society result in a switch in the polarization of the political spectrum.

The most significant achievements of the democratic revolutions were guaranteed civil rights, political freedom, and economic freedom. These resulted in a quantum leap in all aspects of human activities. Those involved with science, technology, architecture, literature, and art reached unprecedented achievements. Society became more developed, knowledgeable, and heterogeneous, producing a vast amount of different politicophilosophical ideas. 
Therefore, the second event after the democratic revolutions was a broadening of the political spectrum. This expansion occurred only during the development of capitalism and democratic institutions. No other political orders have resulted in anything similar in the entire history of mankind. When radical changes are proposed, the political spectrum is shifted to the left, and ideological struggles ensue. When this occurs, the political spectrum widens, because the Right, as status quo, is in principle static and exhibits almost no movement. The Right remained fixed in place until it abandoned its hold by losing the political struggle. The capitalist democratic system was defeated by various currents of socialism in some countries during the twentieth century. The vast majority of the former Communist bloc of Eastern Europe embraced capitalism once again several decades later after their defeat in the Cold War.

Regardless of an imaginary or real switch in the polarization of the political spectrum, the modern political spectrum in question is a progeny of capitalism. No other political system has made possible the coexistence of a great variety of different sociopolitical philosophies, currents, and movements. Ironically, the majority of these philosophies have been trying to dissolve capitalism to varying degrees. Only right-wing ideologies are trying to conserve the gains of the democratic bourgeoisie revolution: the free market, civil rights, and the supremacy of law.

\section{FINDING OBJECTIVITY}

A political spectrum is a system of qualitative comparisons of different political philosophies. Humans try to grasp the main characteristics of political ideologies and sort them by importance, relevance, and usefulness for an individual and society as a whole. The political spectrum is not a natural phenomenon taking place in the physical world but rather a product of human cognitive abilities. It is a subjective perception and valuation of the variety of political thoughts that are generated within society.

People tend to associate themselves with a particular ideology that suits their world view and to reject ones that do not fit their mentality. At present, the political spectrum has become broader and more heterogeneous, since freedom has spawned many different political ideas. People became politically savvy and wise in all the vicissitudes of politics. Therefore, the conditions that determine the classification and ranking of political doctrines 
along a political spectrum have become rather intricate. Moreover, these conditions that differentiate political ideologies have been obscured by political necessities, propaganda and counterpropaganda, human emotions, and historical revisionism.

Whatever arguments one side of the political spectrum brings, the other side refutes with ease. Then, the former rebuffs the latter, and this goes on forever. Thus, it is necessary to present a method that examines the political discourse with neutrality and objectivity. It is essential to find traits that will unambiguously sort ideologies along a political spectrum. What does it mean to belong to the leftist movement? What conditions lead to a particular rightist ideology? What are the mechanisms and factors responsible for the classifications and rankings of political ideas?

Take Italian fascism, for example. Neither the Left nor the Right wants to claim ownership of fascism. There is no consensus among political scientists, sociologists, and economists on the placement of fascism on a political spectrum. Leftists have been so vigorously fighting off fascism that they thrust it to the ultraright position, to the right of classical liberalism. The Right has considered fascism as phenomena of the Left, foremost from the foundational principle that there is nothing to the right of liberal capitalism in a capitalistic society. The founder of fascism proclaimed that fascism superseded both capitalism and Marxian socialism and positioned it neither on the left nor on the right. It was supposed to be an ideology that transcended the left-right paradigm.

The phenomenon of fascism was difficult to grasp, as it contained different elements from both left- and right-wing doctrines. Moreover, the analysis of the problem with fascism has been subject to ideological bias and emotional predisposition. Placing fascism in a specific position on the political spectrum has depended on political correctness and propaganda, not on scientific and objective efforts. Many visualizations of the political spectrum could not put fascism in its historical and ideological place, which arguably invalidates them.

Moreover, scholars have not found agreement on which principal factors influence the placement of a particular ideology along the political spectrum, whether the political spectrum is unidimensional or multidimensional. Scientists have ignored the phenomenon of the switching polarization of the spectrum and the importance of a specific frame of reference when building it. 
The twentieth-century one-dimensional spectrum has communism on the left and fascism and Nazism on the right along with ideologies that support a free market economy. Left-wing academia still adheres to this graphic representation of the political spectrum. However, the positioning of communism and fascism with Nazism on diametrically opposite poles neglects totalitarianism as a critical commonality between all three regimes. In order to bring fascism and communism closer, the linear spectrum was curved to form a circle, as described by McGann (1967.) In the circular spectrum, communism and fascism occupied adjacent positions, correspondingly to the left and the right of the vertical diameter. "Democracy" was positioned on the other side of the circle.

McGann criticized the "circular theory." He pointed out that there is no room in the model for another uncomfortable player in building a spectrum - anarchism - and proposed a modified linear model instead. His model classified political ideology according to the degree of state control and has two cardinal points: anarchy, with 0 percent government regulation, and totalitarianism, with 100 percent state control. "Democracy" falls somewhere in between.

Bryson and McDill (1968) offered a bidimensional model of the political spectrum in which the vertical axis represents the degree of governmental control (statism versus anarchy) and the horizontal axis represents the degree of egalitarianism favored (left versus right). In the same issue of Rampart Journal, Hall (1968) suggested the LFE (lopsided figure eight) theory of the political spectrum. Hall combined the bidirectional spectrum with some circular features. On the $x$ axis, there is "respect for private property," while the $y$ axis denotes "political regulation." The author claimed that his approach combined the best of the circular and linear theories. However, even a glance at the chart would reveal some inconsistencies in the placement of some political doctrines. For example, "collectivist anarchists" are placed on a point with a fairly high degree of "respect for private property," which is not correct.

David Nolan, the founding member of the US Libertarian party, presented his chart in 1971, which depicted different political ideologies along two axes: "Economic Freedom" and "Personal Freedom." His approach seems to be the most promising; however, the question of properly placing fascism and anarchism on the graph remains open for discussion. People still want a definite answer: Which ideology belongs to the Left and what ideology belongs to the Right? 
Scholars have suggested a variety of political spectrum graphs employing different geometries, dimensions, axes, and cardinal points. However, the controversy surrounding the political spectrum has not subsided. In order to change the current state of affairs, it is imperative to find an objective way to assign a particular ism to the Left or to the Right. Therefore, the goal is to find unbiased categories of political philosophies that can unambiguously determine placement on the political spectrum. Such a task entails a comprehensive examination of political doctrines (case studies) and comparison between them (cross-case studies).

The best method of conducting corresponding research in social science is called qualitative comparative analysis (QCA). The research in question differs from the traditional social science investigation in two crucial aspects. First of all, the subject of the study is not a country or a social group, but rather particular characteristics of political ideologies. Secondly, the observable phenomenon is a somewhat artificial mental construct rather than observable social or political fact.

The latter half of the nineteenth century and the first half of the twentieth were rich in generating various political ideologies that changed the social order. Consequently, it is rational to investigate the real and abstract political ideas that flourished at that time. The following political philosophies were selected for examination: Marxism, Trotskyism, social democracy, Marxism-Leninism, Maoism, anarcho-syndicalism, anarcho-communism, revolutionary syndicalism, fascism, National Socialism, conservative liberalism, progressivism, and classical liberalism.

The question that needs to be answered is which factors determine doctrines' polarization. This would further reveal the exact geometry, dimensions, and axes of the political spectrum. The undeniable advantage of QCA is the formalization of the verbal provisions of political doctrines and their translation into the mathematical language of set theory.

\section{QUALITATIVE COMPARATIVE ANALYSIS OF POLITICAL IDEOLOGIES}

Charles Ragin developed qualitative comparative analysis in the late 1990s. Since then, the method has rapidly advanced and become widely used in social studies. In this method, relations between social phenomena are perceived as set relations. In order 
to uncover interconnections between cases and outcomes, QCA therefore employs the mathematical apparatus of set theory, which is based on Boolean algebra.

The domains of this study are political philosophies that constitute a political spectrum. They are verbal by nature and can be stated in terms of sets and set relations. For instance, "conservatism is a right-wing ideology" is equivalent to the phrase "conservatism is a subset of right-wing 'ideologies'"; in turn, "right-wing ideologies are a subset of the whole political spectrum." Moreover, every unique aspect of political ideologies is a member of its corresponding conceptual set. Thus, "revolution" and "evolution" are both elements of the set "methods of change."

The goal of set theoretic methods is to establish explicit connections between sets of interest. QCA assists in identifying commonalities across an array of political ideologies that prompt meaningful empirical connections. This means that QCA could discover causal relationships between political ideologies' attributes and their role in the placement of a particular theory on the political spectrum.

In QCA terms, aspects of political philosophies that are thought to be causes of a phenomenon are called "conditions," while the phenomenon itself is called an "outcome." An outcome in this study is the assignment of a political ideology to the Left or the Right on the political spectrum. In other words, the outcome is political spectrum polarization. Philosophical aspects can be causally linked to an outcome as necessary or sufficient conditions, either by themselves or in combination with others. Thus, set relations are interpreted in terms of sufficiency, necessity, and forms of causalities.

For this study, fuzzy set QCA (fsQCA) was chosen as the most adequate. Fuzzy sets are both qualitative and quantitative. They allow researchers to establish difference in kind between cases (qualitative difference) and determine difference in degree (quantitative difference) between qualitatively identical cases (Schneider and Wagemann 2012). Every political philosophy is considered to be an individual case under the study.

The data on which QCA operates are the membership scores of cases in sets which represent political science concepts. Fuzzy sets explicitly require that the definition of membership values for sets be based on three qualitative anchors: full set membership (1), full 
nonmembership (0), and indifference (0.5). The anchor of indifference is a point of maximum ambiguity; therefore, assigning a 0.5 membership score is not recommended.

For example, "proletariat" is an element of the set "agents of change." A membership score of Marxism-Leninism in the "agents of change" set is 1 , as this theory designates a proletariat as the only force of a socialist revolution. In the case of Maoism, however, the "proletariat" was not a major social influencer. A membership score of Maoism in the "agents of change" set would be a 0 , as it relies on the peasantry as an agent of change. In this example, "proletariat" and "peasantry" are supposed to illustrate two boundary membership values of the "agents of change" fuzzy set.

In general, the membership score in fuzzy sets varies from 0 to 1 and could be any value except the value of maximum ambiguity. In this study, the four-value scheme (table 1) has been employed, which is especially useful in situations where researchers have a substantial amount of information about cases but the evidence is not systematic or strictly comparable from case to case (Ragin 2008).

One of the first tasks in qualitative research is to find aspects (conditions) that describe a political theory best and might influence an outcome. Any mature political theory outlines its positions on designated goals; primary enemies; agents of change; methods of change; scope and pace of implementation; economic and social policies; relations between classes; dealings between state and individuals; questions of nationalism and race; immigration; taxation and tariffs; wages and wealth redistribution; etc.

TABLE 1: VERBAL DESCRIPTION OF FUZZY-SET MEMBERSHIP SCORES

\begin{tabular}{|l|l|}
\hline fuzzy value & the element is: \\
\hline 1 & fully in \\
\hline 0.67 & more in than out \\
\hline 0.33 & more out than in \\
\hline 0 & fully out \\
\hline
\end{tabular}

While seeking the focal, descriptive attributes of political ideologies, careful attention was paid to the questions that caused heated quarrels among the competing philosophical doctrines. Those questions became common points of bifurcation between theories. 
The issue of the "role of a state" alienated anarchists and Marxists, while the question of "scope of change" estranged Trotskyists and Stalinists. After thorough and repeated examination, the following five principal conditions were chosen for QCA:

- Attitude toward private property

- Type of economy

- Wealth redistribution

- Individual freedom

- Nationalism/racism

These aspects of political studies can be considered most relevant in the context of the political struggle in the period between 1850 and 1950 .

"Attitude toward private property" determines whether the means of production are collectivized or remain in private hands. The extreme left ideologies of the period under examination were unconditionally against private property and called for the socialization of all means of production. Reformists set the same goals but in a more gradual way. In any case, the Left aimed to control private enterprise in one way or another. On the contrary, the right ideologies cherished private property. Thus, due to the opposed approaches to private property, collectivization of property $(\mathrm{CP})$ has been included as a condition in the QCA of political ideologies.

"Type of economy" means whether a political doctrine promotes a market economy or a planned one. The Left developed a personal dislike for the market economy. Many leftist political ideologies advocated for a planned economy instead. The right political ideologies, of course, fully supported a market economy with different degrees of regulation. This condition is essential and gains inclusion in the final analysis as PE-planned economy.

"Wealth redistribution" describes a transfer of wealth from one individual or stratum to others by means of expropriation, taxation, welfare, etc., which fuels a plethora of social programs. Political doctrines from 1850 to 1950 suggested a wide scope of social programs ranging from minimal to very generous. The Left usually advocated for the expansion of wealth redistribution programs, whereas the Right sought to keep them to a minimum. This dichotomy prompts the inclusion of wealth redistribution (WR) as condition in the model. 
The attitudes dealing with "individual freedom" range from its complete negation (collectivization of consciousness) to minimal intrusion into private life. Currents on the left had different approaches to this issue. Thus, anarchists promoted a stateless community and complete individual freedom: some viewed a state as a temporary entity, others as the main achievement of the society. The Right traditionally cherished individual freedom, pluralism of opinions, and a nonintrusive state. The issue of personal freedom is therefore included in the qualitative analysis as a potentially significant condition as collectivization of consciousness (CC).

"Nationalism and racism" are self-explanatory attributes, but are extremely sensitive, distorted, and therefore politicized. It is a common perception that the Left was a proponent of internationalism and that nationalism was the trademark of the Right. A careful examination of the different political ideologies and actions of different regimes reveals that nationalism and racism are equally applicable to the doctrines situated at both ends of the political spectrum. Nationalism and racism (NR) could potentially influence an outcome, and therefore is a condition of the analysis.

The next step in fsQCA is defining qualitative anchors that denote full membership (1) and full nonmembership (0) for every condition (aspect of the doctrine) and outcome (place on the spectrum). The qualitative benchmarks that will be used in fuzzy set calibration are presented in table 2 .

\section{TABle 2: Qualitative ANCHORS}

\begin{tabular}{|l|l|l|}
\hline conditions and outcome & full membership (1) & full nonmembership (0) \\
\hline $\begin{array}{l}\text { attitude toward } \\
\text { private property }\end{array}$ & $\begin{array}{l}\text { abolition of } \\
\text { private property }\end{array}$ & $\begin{array}{l}\text { prevalence of } \\
\text { private property }\end{array}$ \\
\hline type of economy & planned economy & market economy \\
\hline wealth redistribution & $\begin{array}{l}\text { generous wealth } \\
\text { redistribution }\end{array}$ & $\begin{array}{l}\text { meager wealth } \\
\text { redistribution }\end{array}$ \\
\hline nationalism/racism & utter denial of bigotry & severe chauvinism \\
\hline individual freedom & $\begin{array}{l}\text { collectivization of } \\
\text { consciousness }\end{array}$ & $\begin{array}{l}\text { stateless society or } \\
\text { unobtrusive state }\end{array}$ \\
\hline political spectrum & left-wing & right-wing \\
\hline
\end{tabular}

There are two cases of political ideologies, which are characterized by full membership and full nonmembership in both 
corresponding conditions and outcome: Marxism-Leninism and classical liberalism.

Marxism-Leninism stood for the complete abolishment of private property $(\mathrm{CP}=1)$, utilized planned economy $(\mathrm{PE}=1)$, built a welfare system $(\mathrm{WR}=1)$, totalitarian state $(C C=1)$, and exerted extreme atrocities on different ethnic groups $(\mathrm{NR}=1) .{ }^{1} \mathrm{On}$ the contrary, classical liberalism advocated for the prevalence of private property $(\mathrm{CP}=0)$, a market economy $(\mathrm{PE}=0)$, a minimum of wealth redistribution $(\mathrm{WR}=0)$, full individual freedom $(C C=0)$, and international trade $(\mathrm{NR}=0)$.

Undoubtedly, Marxism-Leninism is a left-wing political doctrine (Left $=1)$, as it actively seeks the destruction of the democratic state and complete collectivization of the means of production. There is no uncertainty that classical liberalism is a genuine right-wing ideology $($ Left $=0)$, guaranteeing property rights and individual freedom. These ideologies are complete opposites based on their membership scores in their corresponding condition configurations and outcomes.

TABLE 3: TWO POLAR IDEOLOGIES AND THEIR MEMBERSHIP SCORES

\begin{tabular}{|l|l|l|l|l|l|l|}
\hline ideology & CP & PE & WR & NR & CC & spectrum \\
\hline Marxism-Leninism & 1 & 1 & 1 & 1 & 1 & 1 - Left \\
\hline classical liberalism & 0 & 0 & 0 & 0 & 0 & 0 - Right \\
\hline
\end{tabular}

The rest of the political philosophies considered, whose ideas are also grounded in the interpretation of the five main factors used in this study, lie between these two extremes. Their membership scores in corresponding sets have to be determined through a calibration procedure.

There are two methods of calibration suggested in fsQCA: direct and indirect. Both methods imply calibration of fuzzy sets

\footnotetext{
${ }^{1}$ Faithful Leninists carried out a policy of coerced Russification: they closed national schools, newspapers, magazines, and houses of worship. The Soviet regime repressed Don Cossacks; deported Poles, Ukrainians, Moldovans, and people from the Baltic states; resettled Volga Germans, Crimean Tatars, Chechens, and Ingush in other territories; starved 4 million Ukrainians to death during the Holodomor; and were outright anti-Semitic. Only Stalin's death saved Soviet Jewry from a genocide that could match the Nazi one (Gindler 2019a).
} 
using external criteria. In the direct method, values of external standards (economic indexes, for example) are assigned to the corresponding three qualitative anchors (full membership, full nonmembership, and the crossover point). Then, these benchmarks are used to transform the original interval-scale values into fuzzy membership scores. In the indirect method, the researcher performs an initial sorting of cases into different levels of membership, assigning different levels of preliminary membership scores and then refining these membership scores using the interval-scale data.

These techniques assume that interval-scale external indicators exist for every condition and outcome. Unfortunately, a study of political spectrums does not possess such a luxury. There are several reasons for this. The subjects under study are political theories that are abstract ideas, not real social facts. If an idea has never been put in practice, the external standards cannot be appropriately applied to it. For those political ideas that have been institutionalized, some conditions still could not be correlated with existing external indicators. Moreover, for such conditions that can be explained using external standards, the data does not go back chronologically, i.e., to the latter half of the nineteenth century, as much as necessary in order to properly calibrate all the cases. External data could calibrate some of the conditions; nonetheless, it is not advisable to utilize different methods to score membership assessment across various cases and conditions.

Does this mean that a fuzzy set analysis of political ideologies is inappropriate? The answer is definitely no. It is possible to refine the initial membership scores in the indirect method but by some other external procedure. For this purpose, the Delphi method was employed. The Delphi method is a process that involves interaction and cooperation between the researcher and a group of experts proficient in the subject under study. Initially, this method was used in the forecasting procedures and, like any forecast endeavor, it had mixed results. In the study of political spectrums, such prognosis is not an aim. On the contrary, experts are looking back at historical processes and facts that were not systematized, enumerated, or ranked. These circumstances simplify experts' work, as they need to systematize existing knowledge. Thorough interactions and collaborations between the researcher and experts resulted in the refined fuzzy sets presented in table 4 . 
TABLE 4: FuZZY SETS OF POLITICAL DOCTRINE, CASUAL CONDITIONS, AND MEMBERSHIPS SCORE

\begin{tabular}{|l|l|l|l|l|l|l|}
\hline political ideology & CP & PE & WR & NR & CC & Left \\
\hline Marxism-Leninism & 1 & 1 & 1 & 1 & 1 & 1 \\
\hline orthodox Marxism & 1 & 1 & 1 & 0 & 1 & 1 \\
\hline Trotskyism & 1 & 1 & 1 & 0 & 1 & 1 \\
\hline Maoism & 1 & 1 & 0.67 & 0.33 & 1 & 1 \\
\hline anarcho-syndicalism & 1 & 0.67 & 0.67 & 0 & 0.67 & 1 \\
\hline revolutionary syndicalism & 0.67 & 0.33 & 0.67 & 0.33 & 0.67 & 1 \\
\hline anarcho-communism & 1 & 0.67 & 1 & 0.33 & 0.67 & 1 \\
\hline social democracy & 0.67 & 0.67 & 0.67 & 0.33 & 0.67 & 0.67 \\
\hline progressivism & 0.67 & 0.33 & 0.67 & 0.67 & 0.67 & 0.67 \\
\hline fascism & 0.67 & 0.67 & 0.67 & 0.67 & 1 & $?(0.67)$ \\
\hline National Socialism & 0.67 & 0.67 & 0.67 & 1 & 1 & $?(1)$ \\
\hline conservative liberalism & 0 & 0 & 0.33 & 0 & 0.33 & 0 \\
\hline classical liberalism & 0 & 0 & 0 & 0 & 0 & 0 \\
\hline
\end{tabular}

The first task was to find factors that deterministically classify a political doctrine as leftist. Therefore, only parameters that have universal consensus were chosen for the outcome (Left). Outcomes for fascism and National Socialism were intentionally marked "?," as there is no consensus among scholars in the placement of these regimes on the political spectrum. This means that neither fascism nor Nazism were taken into account in the initial iterations of mathematical calculations.

A further assay was to build a truth table. A truth table is the main instrument in analyzing casual complexity. It is evident that the same outcome, for example, "ideologies leaning to the left," can be achieved via several different combinations of casual conditions. In QCA, such combinations are customarily called "recipes," or configurations. A truth table consists of all logical configurations and corresponding outcomes. The main goal of a truth table analysis is to identify explicit casual connections between "recipes" and outcomes (Ragin 2008).

A truth table differs from the data matrix presented in table 4 , where every row denotes a different case. In a truth table, each row instead represents one of the logically possible outcomes AND combinations between the conditions. A truth table that is derived from a fuzzy set establishes a qualitative difference between cases above the anchor of maximum ambiguity-0.5 (more in than out) - and cases below that point (more out than in). As every single condition may be either present or absent, there are $2^{k}$ total rows in 
the truth table, where $k$ is the number of conditions. Since the model consists of five conditions, there are thirty-two rows in the table. Among the thirty-two cases, only thirteen have been "observed." 2 Neither empirical nor abstract evidence is available for the rest. They are, in essence, thought experiments, called counterfactual cases.

Each set constitutes one dimension of the vector space. The five fuzzy set conditions produce a five-dimensional space. Each corner of the space represents one specific combination of the two extreme values that are possible in fuzzy sets - full membership (1) and full nonmembership (0). For each condition, the ones and zeros indicate the different corners of the vector space defined by the fuzzy set's causal conditions. Therefore, each corner represents an ideal combination where full membership and nonmembership are clearly defined. In fuzzy set QCA, cases might have partial membership in all rows, but they have a membership higher than 0.5 in only one row. Consequently, each case is allocated to that particular ideal row which it fits best.

The fsQCA software developed by Ragin and Davey (2014) was used to construct a truth table from the fuzzy sets in table 4 .

TABle 4: TRUth TABle (EXCLUding FASCISM AND

National Socialism)

\begin{tabular}{|c|c|c|c|c|c|c|c|c|}
\hline CP & PE & WR & NR & $\mathrm{CC}$ & number & left & cases & row consistency \\
\hline 1 & 1 & 1 & 0 & 1 & 6 & 1 & $\begin{array}{l}\text { Orthodox } \\
\text { Marxism } 1.00 \\
\text { Trotskyism } 1.00 \\
\text { Maoism } 0.67 \\
\text { anarcho- } \\
\text { syndicalism } 0.67 \\
\text { anarcho- } \\
\text { communism } 0.67 \\
\text { social democracy } 0.67\end{array}$ & 1 \\
\hline 1 & 0 & 1 & 0 & 1 & 1 & 1 & \begin{tabular}{l|} 
revolutionary \\
syndicalism 0.67
\end{tabular} & 1 \\
\hline 1 & 0 & 1 & 1 & 1 & 1 & 1 & progressivism 0.67 & 1 \\
\hline 1 & 1 & 1 & 1 & 1 & 1 & 1 & Marxism-Leninism 1.00 & 1 \\
\hline 0 & 0 & 0 & 0 & 0 & 2 & 0 & $\begin{array}{l}\text { conservative } \\
\text { liberalism } 0.67 \\
\text { classical liberalism } 1.00\end{array}$ & 0.37 \\
\hline
\end{tabular}

${ }^{2}$ Including cases for fascism and National Socialism. 
"Number" refers to the number of cases with membership greater than 0.5 in that corner of the vector space. Row consistency is the degree to which membership in a given corner of the vector space is a consistent subset of membership in an outcome.

\section{ANALYZING THE TRUTH TABLE}

Reported row consistency, the last column, demonstrates if a specific truth table row's conditions are sufficient for its outcome. In other words, it determines whether a conjunction of five specified conditions is a subset of an outcome set. Causal combinations with consistency scores above the cutoff value ( 0.85 is recommended) are assigned to be subsets of the outcome and are coded 1. If a conjunction of conditions scores below the cutoff value, it is not a subset of the outcome, and it is coded 0 (table 2). The four upper rows in the truth table above scored 1 in the "Left" (outcome) column. It can be understood that the conditions of the rows that score 1 in the outcome are sufficient for the outcome to occur. In other words, there are four combinations of causal conditions that are sufficient to bend a political ideology to the left.

However, the goal is to single out the main factors that influence the polarization of the political spectrum. Thus, a more laconic and parsimonious answer is needed. For this, fsQCA is employed by the Quine-McCluskey algorithm (Quine 1955; McCluskey 1956) to minimize the sufficiency statements presented in the truth table logically. This algorithm uses the simplification rules of Boolean expressions presented in the truth table. If two expressions differ in only one condition but produce the same outcome, then the casual condition that distinguishes the two expressions can be considered irrelevant and can be removed. The end products of the pairwise consecutive logical minimization process are "prime implicants." "Prime implicants" are combined through logical operand "OR" and under certain circumstances could be logically redundant. Some of them can be dropped from the solution term in order to obtain the most parsimonious formula. The Quine-McCluskey algorithm designates a prime implicant as logically redundant if all of the primitive expressions are covered without including it in the solution formula (Schneider and Wagemann 2012).

The subjects of this study are political philosophies. Some of them materialized but died out, and some continue to prosper. Some political ideas have never been institutionalized and continue to 
live in the realm of the ideal. Some of the philosophical thoughts included in this study are illogical utopian descriptions of societies living in paradise. These are here considered counterfactual, imaginary political philosophies that are not worse than existing and documented ideas. Political philosophies are not impossible remainders and could be applied in thought experiments. All political ideas have a right to exist; as such, the counterfactual cases should be included in QCA and should undergo the minimization process. For example, take a look at configurations in table 5 .

\section{TABle 5: EXAMPles OF COUNTERFACTUAL CASES}

\begin{tabular}{|l|l|l|l|l|l|}
\hline imaginary ideologies & CP & PE & WR & NR & CC \\
\hline counterfactual \#1 & 1 & 1 & 1 & 1 & 0 \\
\hline counterfactual \#2 & 0 & 0 & 0 & 1 & 0 \\
\hline
\end{tabular}

The first case describes a political doctrine that neglects private property and the market economy, advocates for extreme nationalism and racism, and desires the implementation of an unobtrusive state. The other political philosophy respects private property and the market economy, preaches bigotry, and advocates for individual freedom. (By the way, this is what right-wing nationalism should look like.) These ideologies are imaginary, but there are no fundamental reasons that such ideas could not be thought of in the past or could not be formulated or their implementation attempted in the future. They are as real as Marxism or Trotskyism in this sense.

Therefore, all types of minimization should be applied in the framework of this research, which would result in the most laconic interpretation of causality between political factors and outcomes. The standard analysis produced the result below.

TABLE 6: QCA PARSIMONIOUS RESUlT

\begin{tabular}{|l|l|l|l|}
\hline conditions & row coverage & unique coverage & consistency \\
\hline $\mathrm{CP}$ & 0.96 & 0.04 & 1 \\
\hline $\mathrm{WR}$ & 0.88 & 0 & 0.96 \\
\hline $\mathrm{CC}$ & 0.88 & 0 & 0.96 \\
\hline
\end{tabular}

Solution coverage: 0.96 , Solution consistency: 0.96 
The results could be interpreted as follows. First, QCA selects three causal conditions that influence the outcome. They are $\mathrm{CP}$ (collectivization of property), WR (wealth redistribution), and CC (collectivization of consciousness). Each selected condition has a very high coefficient of consistency and coverage. Therefore, none can be dismissed as insignificant. The overall solution is characterized by an almost perfect score for coverage as well as consistency. Thus, QCA has produced a robust solution that passes the statistical significance test.

In terms of set theory, the solution is written as follows:

(1) $\mathrm{CP}+\mathrm{WR}+\mathrm{CC} \rightarrow$ Left,

where + is an "or" operand and $\rightarrow$ is subset operand.

Since all three factors (CP, WR, CC) are subsets of the outcome set (Left), they are sufficient conditions for the outcome to occur. In other words, socialization of the means of production, wealth redistribution, and the subjugation of the individual to the collective are the cornerstone provisions of the Left's ideology. And furthermore, the conditions are connected by the "or" operand, which means that if any of the three conditions happen to be true, the whole expression becomes true as well. That is, if a political ideology suggests the collectivization of property (CP is true) but opposes wealth redistribution (WR is false), the doctrine still belongs to the Left.

This result outlines three distinct paths to leftism: collectivization of private property, wealth redistribution, and collectivization of consciousness. Those paths can be employed individually or complement each other. For example, communism utilizes all three paths; evolutionary socialism predominantly employs a wealth redistribution mechanism; and fascism engages in the collectivization of consciousness and introduction of generous social programs. Recall that fascism and National Socialism were specifically omitted from the model. However, the obtained results show the paths to socialism that both odious regimes employed. One can argue that these regimes did not de jure forbid private property, but one cannot dispute the fact that both the Italian fascists and Nazis implemented a totalitarian state and implemented very generous social programs aimed at the comprehensive support of working people.

Therefore, fascism and Nazism genuinely belong to the socialist current, having at least two conditions out of three as true. For their case, the formula takes the following form: 
(2) [CP is false] OR [WR is true] OR [CC is true] $\rightarrow$ [LEFT is true]

It is also worth mentioning that even though private property was nominally allowed, it was controlled by the omnipotent and omnipresent state. To end the ambiguity surrounding fascism and Nazism, it is necessary to firmly state the following: Italian fascism and National Socialism belong to the Left, as they are incarnations of the non-Marxian socialism that utilized collectivization of consciousness rather than the socialization of private property as the primary path toward socialism (Gindler 2019b). And yet state control over the economy ultimately led to the gradual socialization of private property, which made the state de jure owner.

Also note that the condition NR - nationalism and racism - was not selected as a part of the solution, meaning that this factor is not one that needs to be invoked in designing the political spectrum. Indeed, xenophobic inclinations can be attributed to any political doctrine on the left as well as on the right.

At first sight, it may seem like the exclusion of the factor "planned economy" is an anomaly in the model. However, such is not the case. Some exotic socialist currents exclude the state and all services associated with it from their doctrine. The existence of such political theories in the model has effectively eliminated PE from the parsimonious solution.

Fascism and National Socialism can be included back into the QCA model with the following membership scores in the outcome set: 0.67 for fascism and 1 for National Socialism. Then we will recalculate a truth table. Fascism is assigned a score of 0.67 as an acknowledgment that Fascists proclaimed to be forming a society that, at least in theory, was neither right nor left. 
Table 7: Truth table (InCluding fascism and National Socialism)

\begin{tabular}{|c|c|c|c|c|c|c|c|c|}
\hline $\mathrm{CP}$ & PE & WR & NR & $\mathrm{CC}$ & number & left & cases & row consistency \\
\hline 1 & 1 & 1 & 0 & 1 & 6 & 1 & $\begin{array}{l}\text { Orthodox Marxism } 1.00 \\
\text { Trotskyism } 1.00 \\
\text { Maoism } 0.67 \\
\text { anarcho- } \\
\text { syndicalism } 0.67 \\
\text { anarcho- } \\
\text { communism } 0.67 \\
\text { social democracy } 0.67\end{array}$ & 1 \\
\hline 1 & 1 & 1 & 1 & 1 & 3 & 1 & $\begin{array}{l}\text { Marxism-Leninism } 1.00 \\
\text { fascism } 0.67 \\
\text { National Socialism } 0.67\end{array}$ & 1 \\
\hline 1 & 0 & 1 & 0 & 1 & 1 & 1 & $\begin{array}{l}\text { revolutionary } \\
\text { syndicalism } 0.67\end{array}$ & 1 \\
\hline 1 & 0 & 1 & 1 & 1 & 1 & 1 & progressivism 0.67 & 1 \\
\hline 0 & 0 & 0 & 0 & 0 & 2 & 0 & $\begin{array}{l}\text { conservative } \\
\text { liberalism } 0.67 \\
\text { classical } \\
\text { liberalism } 1.00\end{array}$ & 0.37 \\
\hline
\end{tabular}

The standard analysis of the truth table (table 7) led to virtually the same solution, with high coefficients of coverage (0.97) and consistency (0.94), described by the formula (1). Once again, it is essential to remember that formula (1) determines that CP, WR, and $C C$ are sufficient conditions to bend a political ideology to the left. Are these conditions also necessary? In order to answer this question, QCA provides an analysis of the necessary conditions.

A necessity test was performed by the same software that was used in the truth table analysis. The result is presented in table 8. The consistency score was sorted in descending order. With a liberal cutoff value of 0.85 , only three individual conditions passed the necessity test. Neither "planned economy" nor "nationalism/ racism" made the cut. 
TABle 8: ANALYSis OF NECESSARY CONDITIONS

\begin{tabular}{|l|l|l|}
\hline condition & consistency & coverage \\
\hline $\mathrm{CP}$ & 0.93 & 1.00 \\
\hline $\mathrm{CC}$ & 0.90 & 0.93 \\
\hline $\mathrm{WR}$ & 0.87 & 0.96 \\
\hline $\mathrm{PE}$ & 0.80 & 1.00 \\
\hline $\mathrm{NR}$ & 0.47 & 1.00 \\
\hline
\end{tabular}

Thus, it can be concluded that socialization of property, wealth redistribution, and collectivization of consciousness are necessary and sufficient conditions of a left-wing ideology, and that any one of them when true uniquely identifies a political philosophy as leftist. Consequently, these findings lead to a comprehensive definition of socialism.

Socialism is a set of artificial socioeconomic systems which is characterized by varying degrees of socialization of property and consciousness, scales of wealth redistribution, and the imposition of these on the community by revolutionary or governmental elites without the consent of the population.

The next question that needs to be answered is what configurations of conditions characterize right-wing ideology. For that, it is necessary to analyze the outcomes denoted as $\sim$ Left (NOT Left) in truth table. The algorithm to find the solution remains the same and brings similar results to formula (1). That is,

(3) $\sim \mathrm{CP}+\sim \mathrm{WR}+\sim \mathrm{CC} \rightarrow \sim$ Left,

where + is "or" operand and $\rightarrow$ is subset operand.

The formula reads that respect for private property rights, the negation of wealth redistribution, and cherishing of individual freedom are sufficient conditions to bend a political ideology to the right. If any of these conditions happen to be true, the political doctrine is defined as right-wing. The analysis of necessary conditions shows that $\sim \mathrm{CP}$ and $\sim \mathrm{WR}$ are statistically valid, whereas $\sim \mathrm{CC}$ has a low consistency level of 0.78. As the number of cases of right-wing ideologies in this model is small, these cases are allowed a lower consistency threshold for the necessity test.

Anarchism and libertarianism seem to both advocate for individual freedom. However, the stateless society advocated by anarchists does not guarantee the degree of individual freedom promoted by libertarians. For example, Anarcho-communism first materialized in 
Ukraine from 1918 to 1921 during the revolution in the Russian Empire (Voline 2019). Stateless, multinational communities were organized in a "free territory" in southeastern Ukraine that contained approximately 7 million people. They lived during a time of extreme calamities under the protection and strict regulation of Nestor Makhno's Revolutionary Insurrectionary Army. Anarchists conducted a social experiment by building a society according to their theoretical provisions but under the umbrella of powerful military forces. The population was subordinated to the dominant political idea that prevailed in these territories. That is why the membership score in "Collectivization of Consciousness" for anarchists is 0.67 instead of 0 .

Thus, anarchists' call for liberty does not preclude the collectivization of consciousness. Moreover, it will be shown further that full personal liberty cannot be achieved without complete economic freedom. Even so, anarcho-communists carried out a policy of socialization of private property. Therefore, the degree of freedom attained by anarchists does not reach the bar set by the libertarians.

The solution for the outcome "Right" exhibits complete symmetry with the answer derived for "Left," which is as follows:

$\mathrm{CP}+\mathrm{WR}+\mathrm{CC} \rightarrow$ Left is a mirror image of $\sim \mathrm{CP}+\sim \mathrm{WR}+\sim \mathrm{CC} \rightarrow \sim$ Left.

This fact allows for the assertion that all three conditions affect the polarization of the entire political spectrum. Thus, we have found the factors that can be used in the construction of objective spectrograms. Given one dependent variable-political spectrumand three independent variables $-\mathrm{CP}, \mathrm{WR}$, and $\mathrm{CC}$ - the spectrum would be four-dimensional. However, it is impossible to visualize a four-dimensional space. That is why it is necessary to sacrifice one dimension, i.e., one parameter has to be eliminated. The best candidate for such elimination is $\mathrm{WR}$ - wealth redistribution.

It can be assumed that the redistribution of wealth is a form of systematic and gradual encroachment on private property. Suppose an entrepreneur has capital, $C$, which makes a profit, $P$. The state confiscates part of the profit in favor of others, using progressive taxation; therefore, the profit becomes $P^{\prime}$, where $P<P^{\prime}$. An entrepreneur could earn a smaller profit of $P^{\prime}$ with less capital, $C^{\prime}$, that is, $C^{\prime}<C$, with no progressive tax. Therefore, the state reduces the productive capital of a businessman by the amount $C-C^{\prime}$. Wealth redistribution is latent socialization of the means of production. Thus, it is reasonable to assume that wealth redistribution is reflected in the parameter "collectivization of property." That is why it is safe 
to eliminate WR from the model without significant deficiency.

The new formulae would be as follows:

$$
\mathrm{CP}+\mathrm{CC} \rightarrow \text { Left }
$$

(4) $\sim \mathrm{CP}+\sim \mathrm{CC} \rightarrow \sim$ Left

It reads that collectivization of property or assault on individual freedom defines the left political doctrine. Inversely, respect for private property rights or personal freedom defines the right ideology.

Now it is possible to build a political spectrogram in three-dimensional space. Let us denote the $x$ axis as Economic Freedom, the $y$ axis as Individual Freedom, and the $z$ axis as Political Spectrum. Political Spectrum has a range from 0 to 1 , where point 0 corresponds to the Left and point 1 to the Right. The $x$ and $y$ axes also have unit lengths. Specific values which correspond to Economic Freedom and Individual Freedom are derived for each political philosophy from membership assessments for $\mathrm{CP}$ and CC conditions, (table 1). However, for better visibility, the inverse value is used: 1 becomes $0,0.33$ becomes 0.67 , and so forth. Figure 1 presents the theoretical spectrogram of political ideologies in tridimensional space.

FigURE 1: SPECTRUM VS. ECONOMIC FREEDOM, PERSONAL FREEDOM

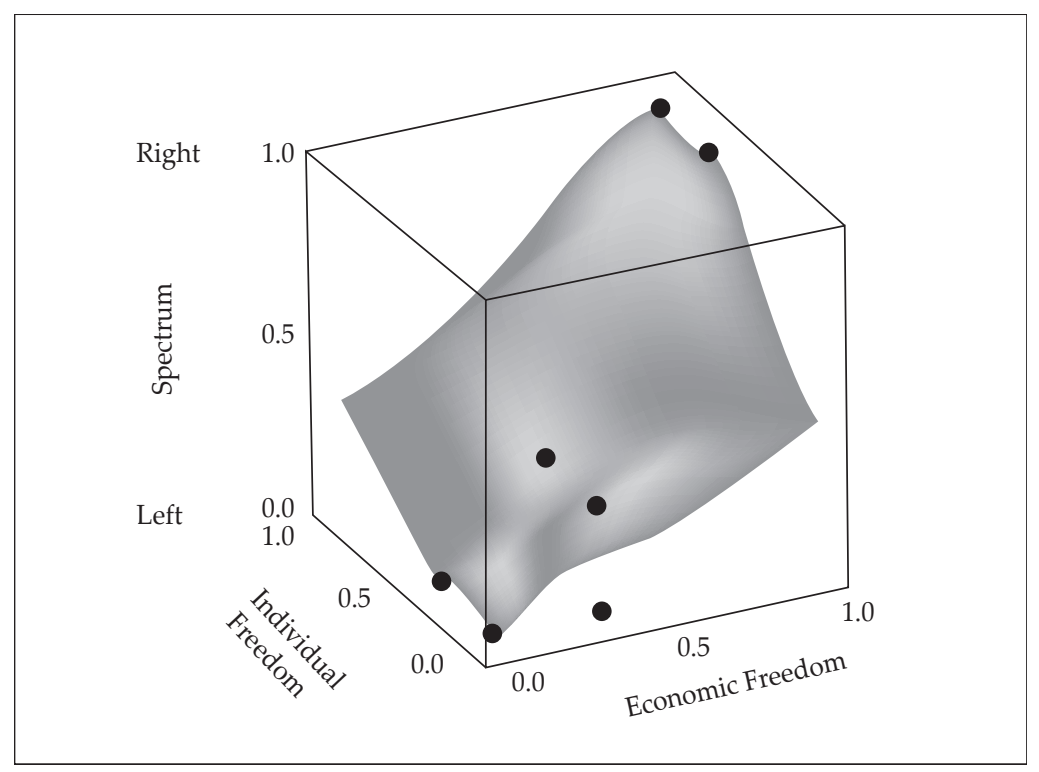


The graph has the form of a falling leaf, in which the upper end corresponds to the parameters of the ideologies leaning toward the right wing. Thus, at the very peak are political philosophies advocating for maximum personal and entrepreneurial freedom. As the values of individual and economic liberties decrease, the leaf expands in the center, and then it reaches the bottom. The lower end corresponds to the totalitarian ideologies with minimum values for personal and economic freedom. All other ideologies are located on the body of the leaf between these two extremes. However, each one has its respective mark on the spectrum axis. Therefore, different combinations of economic and personal freedoms correspond to particular spots on the political spectrum.

It should be recognized that the three-dimensional representation of the spectrogram is still not convenient for analysis and comprehension. In order to simplify visualization, it is better to represent a three-dimensional figure on a two-dimensional plane. In order to do this, let us cut the three-dimensional figure with planes that are parallel to a coordinate plane $X x, Y y$ (Economic Freedom, Individual Freedom). Every cutting plane produces plane sections that are called contour lines. A contour line for a function of two variables is a curve that connects points where the function has the same particular value. Thus, every contour line will correspond to the value of the same spectrum.

\section{Figure 2: Political SPectrum Contour Plot}

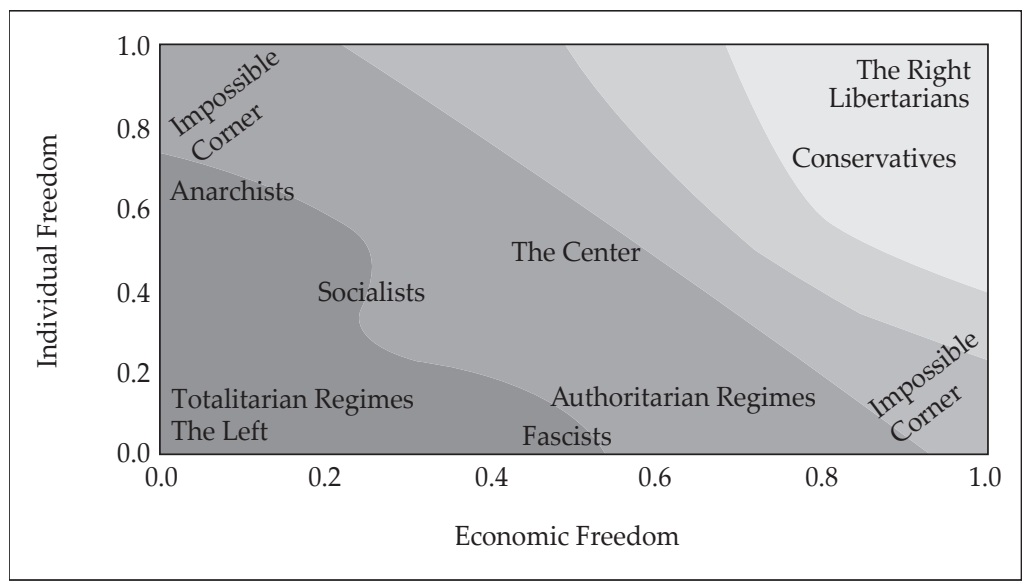

Figure 2 represents the contour lines of the political spectrum that are cut with a pitch of 0.2. The graph is divided into five regions that are all characterized by an equal spectrum range. Indeed, 
different combinations of $x$ and $y$ values can determine entry into an area with the same spectrum range. The upper right-hand corner corresponds to political philosophies that are distinguished by high values for individual and economic freedom. These are real right-wing ideologies that occupy a relatively small area and have political spectrum values from 0.8 to 1.0.

The right-wing ideologies occupy a plateau separated from the centrist ones by a steep slope. The slope derives from the small interval between the adjacent contour lines with spectrum values of 0.6 and 0.4. Further, the spectrum expands as the distance between contour lines increases. Thus, left centrist and hard-core left-wing ideologies are located on a wide, gentle slope. This is an indicator that the spectrum inflates to the left. The left totalitarian regimes are at the bottom, having individual freedom and economic freedom values close to zero. Authoritarian regimes have a low magnitude of individual freedom and moderate values for economic freedom. They are located to the right of the totalitarian regimes and below centrists.

The upper-left and lower-right areas are marked as impossible corners. The former has a high degree of individual freedom and a minimal magnitude of economic freedom; the latter has a high level of economic freedom and a low level of individual freedom. The reason for this label follows from the presence of a positive correlation between the degree of individual freedom and the level of economic freedom.

\section{Figure 3: FitTed Line PLOT}

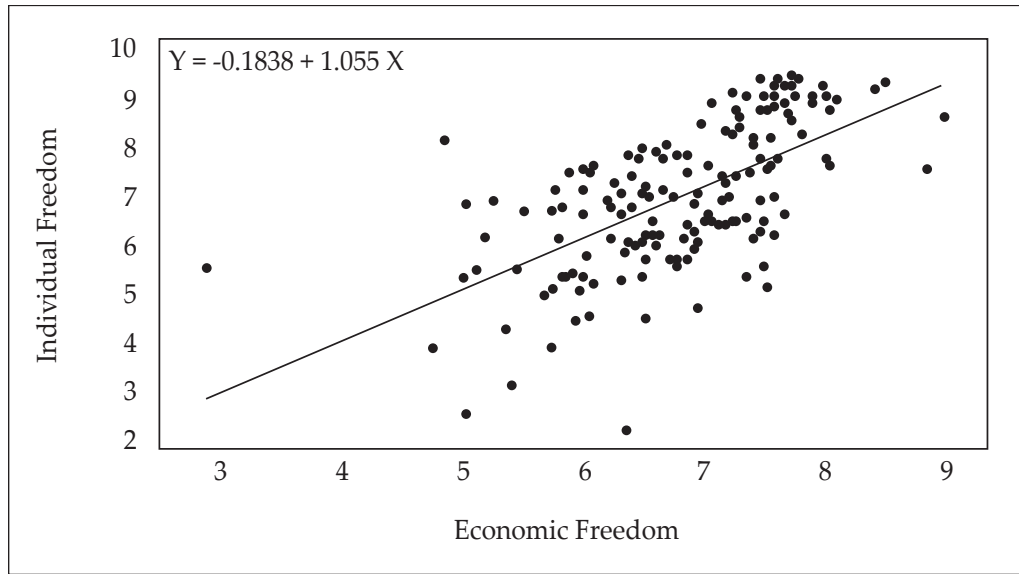

The concept of the socialization of private property and the collectivization of consciousness in a broad sense can be most 
adequately described by indices of economic freedom and individual freedom, calculated in the framework of the Human Freedom Index. The Human Freedom Index describes the state of human freedom in the world based on a broad measure that encompasses personal, civil, and economic freedom. The report is copublished by the Cato Institute, the Fraser Institute, and the Liberales Institut at the Friedrich Naumann Foundation for Freedom (Vásquez and Porčnik 2018).

Correlation analysis between two vectors of freedom determined a significant degree of a positive correlation between them, $r=0.67$. It means that an increase in the level of economic freedom leads to an increase in individual freedom and vice versa. The equation of the fitted line plot (figure 3 ) essentially reads $y=x$. The line is diagonal, because the angle of inclination with respect to the $x$ axis is forty-five degrees. This means that each unit of increase in the amount of economic freedom leads to a unit of increase in individual freedom. When economic freedom is at its maximum, one should see maximum individual freedom. Correspondingly, a minimum of economic freedom predetermines a minimum of individual freedom. Therefore, the upper left-hand and the lower right-hand corners, which correspond to a minimum of economic freedom and a maximum of individual freedom, on the one hand, and a maximum of economic freedom and a minimum of individual freedom, on the other, constitute impossible combinations. Collectivist anarchists would never achieve a maximum of personal liberty while having a low degree of economic freedom. A coarse despotism will never create a society with a high level of economic freedom.

The indices of economic and individual freedom act as proxies for the theoretical concepts of the socialization of private property and the collectivization of consciousness. They were calculated for individual countries instead of distinct political philosophies. What kind of external index could serve to provide values for an initial approximation for the conceptual left-right political spectrum? The historical data suggests that right-wing political theories are responsible for inducing democratic transformation in society. At the same time, various left-wing ideologies tend to build up totalitarian and authoritarian states. That is why it is plausible to utilize an index of democracy to roughly represent a political spectrum polarization by countries. 
In addition to the indices of economic and individual freedom, this study uses the Democracy Index, a product of a UK-based company called The Economist Intelligence Unit (EIU) (The Economist 2018). This index classifies countries by four categories: full democracies, flawed democracies, hybrid regimes, and authoritarian regimes.

Thus, indices for the analysis were created by two different institutions that each employed a unique methodology. After the direct recalibration of index data to the interval [0,1], it became possible to build a three-dimensional graph of degree of democracy versus individual and economic freedom (figure 4). The first thing that catches the eye is the similarity of the leaf-shaped graph to the theoretical surface of figure 1. Closer to the center and the bottom, the surface became more wrinkled, which is expected for the unprocessed data; However, the trend remains the same. Countries with high values of economic and individual freedom occupy the plateau. Totalitarian states are at the bottom, whereas in the middle there are countries with mixed regimes.

Figure 4: Degree of Democracy versus individual AND ECONOMIC FREEDOM

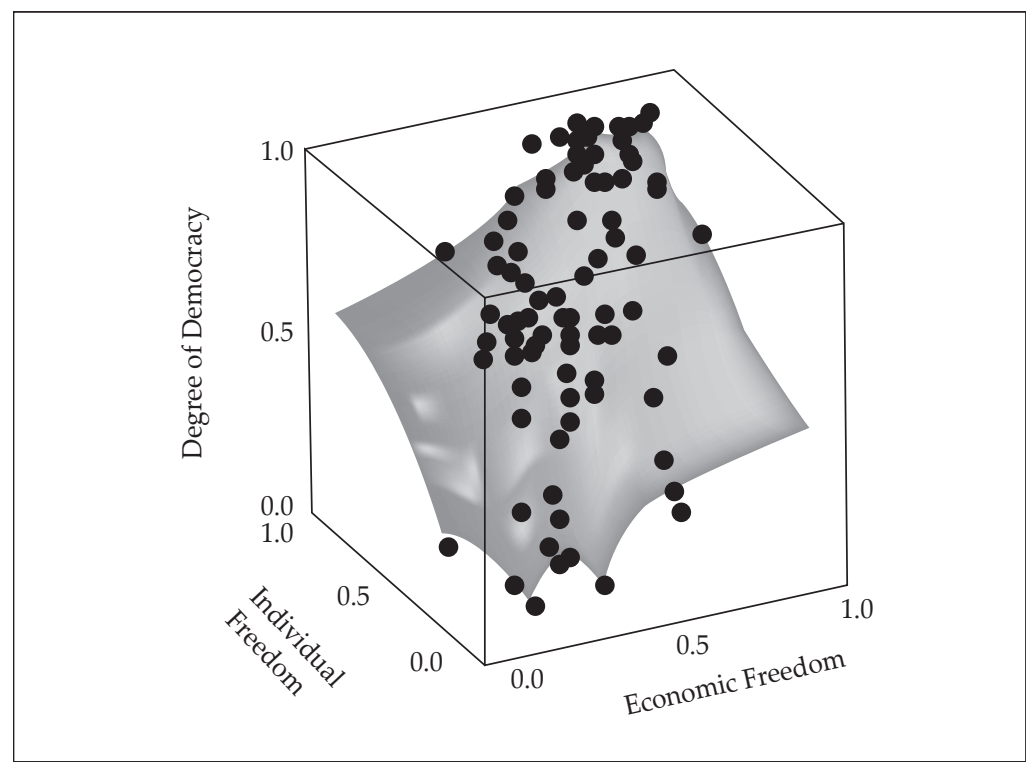

This dispersion is most clearly seen in the contour plot (figure 5). The graph has retained a feature depictured for the political 
spectrum (figure 2). The contour line divided the graph into five zones with different degrees of democracy. There are some irregularities that, for the most part, could be explained by the differences in experts' estimates and opinions of the data. Thus, the developers of the Human Freedom Index assigned Argentina a low economic freedom score, but the EUI experts assigned it a high one for degree of democracy. Argentina is a clear outlier. On the opposite side are Bahrain and the United Arab Emirates, which are classified as authoritarian regimes (which is correct) but score pretty highly in the level of economic freedom. These countries should be placed closer to Saudi Arabia, which bears the same political, economic, and cultural characteristics. Nevertheless, regardless of a few outliers, the graph demonstrates that there are no countries that simultaneously have a high level of individual freedom and a low degree of economic freedom. The combination of a high value of economic freedom and a low level of individual freedom is implausible as well.

\section{Figure 5: Countour Plot: DegreE OF DEMOCRACY}

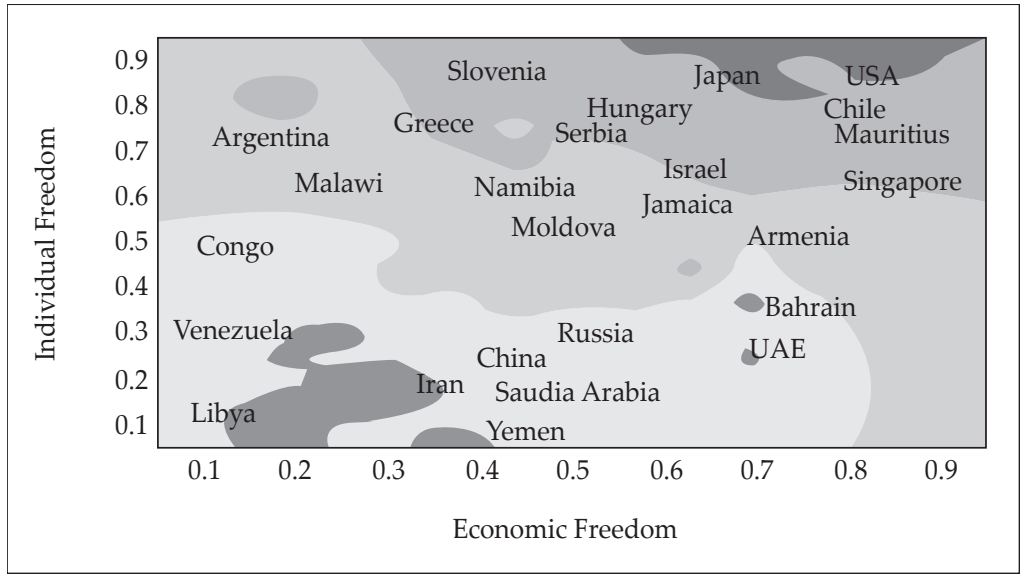

Countries in the upper right-hand corner enjoy economic prosperity. Their average per capita income $(\$ 39,249)$ is significantly higher than those of the other quartiles; the average per capita income in the least free quartile is $\$ 12,026$ (Vásquez and Porčnik 2018).

Right-wing ideology, which builds on the notion of individual freedom and respect for private property, creates a prosperous society, whereas proponents of leftist ideology-collectivization 
of private property and consciousness-run societies to misery. The state of affairs in Venezuela is a vivid example; the country deteriorated within two decades. It should be noted that even in developed, industrial countries there is a continuous political battle between the keepers of the status quo - the rightists - and proponents of "change"-the leftists. The war of ideologies goes on with varying success. However, the graph shows that if the leftist idea wins, there is only one direction away from the comfortable plateau-downhill.

Now, let us draw a schematic plot of the political spectrum, bearing in mind the features that have been discovered. The upperleft and lower-right areas are impossible corners. The upper-right region with a maximum degree of both freedoms is a tiny spot that only about two dozen societies have been able to occupy in Fig. 6 . The spectrum is inflated to the left. Thus, the central area with a mixed degree of both freedoms is rather large. The packet of utter misery is in the lower left-hand corner. This area is much smaller compared with the centrists' area but more prominent than the area of prosperity. The lines of the political spectrum values delimit each area.

\section{Figure 6: SPECTRUM DiAgRAM}

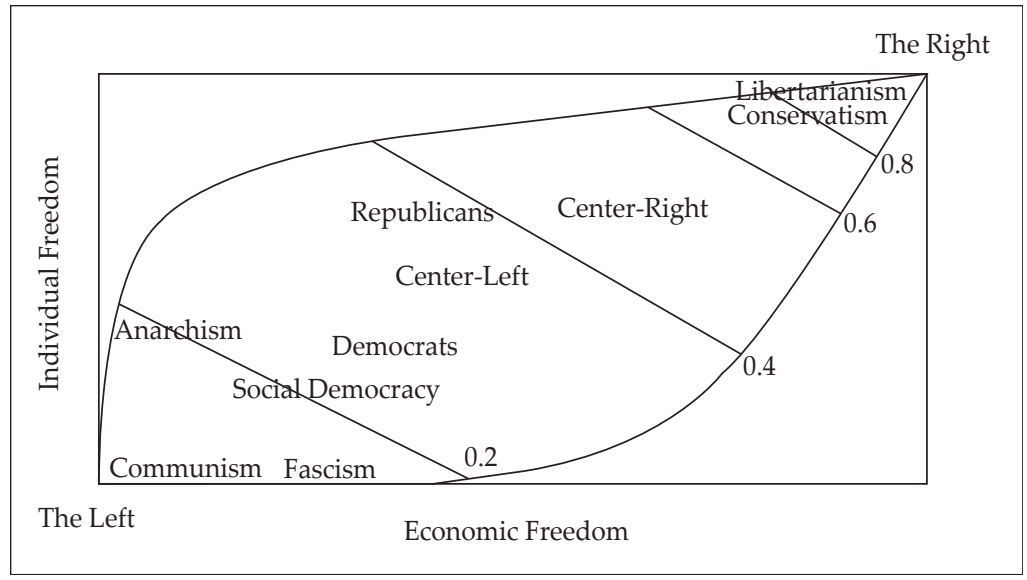

\section{CONCLUSION}

When building a political-philosophical spectrogram, scientists faced many obstacles, many of which were ideological. The shape of the graph was influenced by the compiler's personal preferences and biases. The most challenging task was appointing suitable 
positions to anarchism, fascism, and Nazism. Different factors, dimensions, axes, and cardinal points have been used in different political spectrograms. Most often, the graphs do not complement each other, and it seems that each of them describes an entirely different reality. There was an urgent need to conduct an objective analysis of political philosophies and find the factors that influence the political spectrum's polarization. These conditions would determine the geometric dimensions of the spectrogram and its principal axes. For these purposes, the qualitative comparative analysis (QCA) was used, as it allowed the introduction of a fraction of objectivity due to the use of a formalized mathematical apparatus of the theory of sets.

QCA helped to identify the most concise causal conditions that influence the bending of an ideology to one side or the other. Thus, it was found that spectrum polarization depends on three conditions: attitudes toward private property $(\mathrm{CP})$, individual freedom (CC), and wealth redistribution (WR). It should be noted that these factors are both sufficient and necessary and statistically reliable. They influence both wings of the political spectrum. The ideology is left leaning if it advocates for the socialization of private property, collectivization of consciousness, and generous wealth redistribution. These three factors denote different paths to socialism, and even if just one of them is present, the ideology or regime is belongs to the Left. Communists utilized all three ways to achieve a "paradise"; evolutionary socialists employed wealth redistribution as the primary path; National Socialists and Fascists used subjugation of the individual to the collective and wealth redistribution; collectivist anarchists were engaged in the collectivization of property. On the contrary, the ideology is right leaning if it respects private property and individual freedom and declines excessive wealth redistribution.

With firmly determined factors that influence the political spectrum's polarization, it became possible to build a spectrogram unambiguously. However, a function of three variables can be presented only in four-dimensional space, which is quite challenging to visualize. Therefore, one condition had to be eliminated. The wealth redistribution factor was chosen, because it can be regarded as inherently a latent collectivization of the means of production meaning that its influence can be reflected in the socialization of property. Moreover, the Economic Freedom 
Index has already considered the impact of such governmental monetary and fiscal actions.

The spectrogram was presented as a contour plot where each contour line divided the graph into regions. The resulting graph resembled the trimmed Nolan chart, as it is utilized the same axes; however, it should be remembered that this is a two-dimensional representation of the three-dimensional surface, which reflects "leftright" polarization of the political spectrum. The political spectrum developed here ranges from 0 to 1 , where the left-leaning political philosophies are grouped closer to 0 , and the right leaning ones are in the proximity of 1 . In our example, the values of the political spectrum from 0.8 to 1 are occupied by the right-wing ideologies. On the opposite end, the interval between 0 and 0.2 is reserved for hard-core leftist doctrines. The rest of the political philosophies are in between. Therefore, even though the two-dimensional contour plot was derived from a three-dimensional model, it is still makes it possible to classify doctrines along the left-right axis, which is especially convenient for a layperson.

It is very plausible to use economic and individual freedom indices as proxies for the causal factors in our model. Very roughly, an index of democracy can be used as a representation of political spectrum polarization. Nevertheless, using those indices in this model showed a good match between the theory and reality. There is a significant positive correlation between two vectors of freedom. This means that an increase in the magnitude of one leads to a rise in the other. The regression line has a form of $y=x$, which effectively eliminates two combinations of factors from consideration. Thus, maximal economic freedom cannot coincide with minimal individual freedom. Also, maximal individual freedom is incompatible with minimal economic freedom. These combinations of factor values are reflected in the graphs as impossible corners. Therefore, spectrograms schematically can be presented in the shape of a leaf crossed by spectrum lines. A user can plot different ideologies and regimes on the graph and grade them along available axes, including one-dimensional classification as well.

\section{REFERENCES}

Bryson, Maurice C., and William R. McDill. 1968. "The Political Spectrum: A Bi-dimensional Approach." Rampart Journal 4, no. 2: 19-26.. 
The Economist Intelligence Unit. 2018. Democracy Index 2018: Me Too? Political Participation, Protest and Democracy. N.p.: The Economist.https:// www.eiu.com/public/topical_report.aspx?campaignid=democracy2018.

Gindler, Allen. 2019a. "What Did Marx and Engels Think of Other Races?" American Thinker, April 22, 2019. https://www.americanthinker.com/ articles/2019/04/what_did_marx_and_engels_think_of_minorities.html.

_.2019b."FascismHasAlwaysBeenanEnemyofPrivateProperty."Mises Wire, June 6, 2019. https://mises.org/wire/fascism-has-always-beenenemy-private-property.

Hall, Bowman N., II. 1968. "The L.F.E. Theory of the Political Spectrum." Rampart Journal 4, no. 2: 27-31. https://cdn.mises.org/Rampart_ summer1968_2.pdf.

Knapp, Andrew, and Vincent Wright. 2001. The Government and Politics of France. 4th ed. New York: Routledge.

McCluskey, E. J. 1956. "Minimization of Boolean Functions." Bell System Technical Journal 35, no. 6: 1417-44.

McGann, Lawrence. 1967. "The Political Spectrum." Rampart Journal 3, no. 4.

Quine, W. V. 1955. "A Way to Simplify Truth Functions." American Mathematical Monthly 62, no. 9: 627-31.

Ragin, Charles C. 2008. Redesigning Social Inquiry: Fuzzy Sets and Beyond. Chicago: University of Chicago Press.

Ragin, Charles C., and Sean Davey. 2014. fs/QCA [computer program]. Version 2.5/3.0. Irvine, Calif.: University of California.

Schneider, Carsten Q., and Claudius Wagemann. 2012. Set-Theoretic Methods of the Social Sciences. New York: Cambridge University Press.

Vásquez, Ian, and Tanja Porčnik. 2018. Human Freedom Index 2018: A Global Measurement of Personal, Civil, and Economic Freedom. [Washington, D.C.?]: Cato Institute, Fraser Institute, and Friedrich Naumann Foundation for Freedom. https://www.cato.org/sites/cato.org/ files/2021-01/human-freedom-index-2018.pdf.

Voline. 2019. The Unknown Revolution 1917-1921. Oakland, Calif.: PM Press. 